\title{
Investigation on the Objective, Logic, Impetus and Route of Sport Reform in China based on the Background of Comprehensively Deepening Reform
}

\author{
Wang Jian ${ }^{1}$ \\ Tianjin Agricultural University \\ Department of Physical Education \\ Tianjin 300384, China
}

\begin{abstract}
The origin of sport reform must start from "principal contradictions and secondary contradictions" and "social existence and social consciousness" of materialism. Since the "sports reform" was put forward at the Third Plenary Session of the 18th CPC Central Committee, the contradictions of Chinese sport has gradually evolved, positioned and finally returned to the starting point of reality again. Soon afterwards, "advancing the modernization of national sports management system and building the capacity of sports management" has become the general direction and objective to comprehensively deepen sport reform. Sport reform not only tests the motivation of Chinese sport reform but verifies the government's willingness and awareness of reform. Reform requires both theoretical support and "top-down" reform impetus. Therefore, it is necessary to make investigations on comprehensively deepening sport reform, establishing a government with sense of responsibility and accomplishment, creating effective market to realize return of function and cultivating organic society to improve performance.
\end{abstract}

\section{Keywords-Sport reform; Objective; Logic; Impetus; Route}

\section{INTRODUCTION}

Sports can reflect the social and economic characteristics of a certain historical period, which is the social culture with sign of times. At present, our country is in the process of building a moderately prosperous society in all respects and there are earthshaking changes in politics, economics and culture in the new era, while sport reform lies in a nonplussed situation. According to the incomplete statistics, since 2000 till 2015 there have been 93 in $100 ; 8491$ in 10,$000 ; 836974$ in $1,000,000$ adults not having physical training, during which period, there is an increase in the number of patients by 25 percent annually. The statics are astonishing. Since deepening the overall sport reforms was put forward, it has become a topic deserving our mutual consideration how to develop sports to benefit the public and serve social economic construction.

\section{THE OBJECTIVE OF CHINESE SPORTS BASED ON THE} BACKGROUND OF COMPREHENSIVELY DEEPENING REFORM

\section{A. Definition of sports reform objective}

The objective and route complement each other. If we find the definite reform target, we can plan the next reform route and then start from practical needs and make bold speculation by means of awareness and concepts. The objective will change with time. However, at any time, our objective must be distinct and definite. Sports reform is the ultimate target, so we must plan the route and orientation according to sports practice. Sports practice serves as both the realistic start and the final result of sports reform. Then we can make bold speculations of sports reform and make it the end of sports practice.

\section{B. Reform objective of sports practice}

Sports reform is possessed with such characteristics as mutual check, interconnection and mutual complementation, so it is pretty troublesome to push it forward. For example, transformation of sports industry, sports administration, end-toend joint between training system and competition system, coordination of competitive sports and sports for all, complementation between incentive mechanism and commitment mechanism and the relationship between juvenile sports and school physical education are all the great challenges we are facing without any solutions. Too high reform objective sets off the positive interacting relationship between sports and benefits by contrast. It seems like a game between sports resources and realistic requirements. Our reform objective must be stable firstly and exert its role in sports practice reform 


\section{Conprehensively deepening sports reforms}

The focus of deepening the reform lies in the structural system. Under the present political, economic and social background, without characteristics of times or pertinence, the reform target would be difficult to realize the systematic and coordinated sports practice of. Firstly, competitive sports, popular sports, sports education, sports technology and sports industry should be open to the public instead of being separated from what the world requires. Secondly, the reform scheme of sports conflicts with the realistic origin of reform tasks, for sports business represents national business, whose reform target, layout, route and scheme will be restricted by national reform framework. If the pluralistic society structure has formed, there will be more interests separation and conflicting interests. Only "supply and demand" is materialized, can all the aspects of reports reform be optimized.

\section{LOGIC OF CHINESE SPORTS BASED ON THE} BACKGROUND OF COMPREHENSIVELY DEEPENING REFORMS

\section{A. Theoretical foundation of sports reform}

Materialistic dialectics proves "there are contradictions everywhere in the development of things", so it is thought that "reform is to make comprehensive correction". In other words, sports reform is the "correction" of sports development, for there exist contradictions between demand and supply, equality and efficiency and quantity and quality in sports. Since all these contradictions have two sides, their functions are different from each other. Therefore, we divide them into principal and secondary contradictions according to functions. Principal contradictions dominate the sports reform and play the decisive role. Only by suppressing the principal contradictions can we formulate scientific sports reform schemes. For example, only by reforming and innovating reports system according to variation characteristics of sports, interest relationship of sports practice and development environment of sports, can we coordinate sports governance structure and development orientation, thus ultimately accelerating the better development and virtuous cycle of sports.

\section{B. Political logic of sports reform}

Under the background of deepening the overall reforms, the development of sports should be possessed with orientation, strategy and globality. Since CPC Central Committee's Decisions on Economy was raised in the Third Plenary Session of the Eleventh Central Committee, National Athletic Committee has issued Draft about Sports System Reform and Opinions on Deepening Sports Reform successively, which displays fully the national decision to mobilize strength from all the aspects to reinforce sports and overall deployment of social market benefits to coordinate sports mechanism and operation mechanism, as well as laying a solid foundation of economy, politics and society. In addition, the Party advocated "deepening the overall reforms" in the Third Plenary Session of the Eighteenth Party Congress and pointed out "promoting market to play a decisive role in resource allocation" and "national governance system and modernization of governing capacity" were the ultimate objective of deepening the overall reforms in China. General Planning of Chinese Football Reform and Opinions on Accelerating the Development of
Sports Industry and Promoting Sports Consumption issued by the state are the two supporting points of Chinese sports reform. In addition to assessing the situation, sports reform scheme should also recognize the reform objectives and find the correct orientation of sports governance modernization [3].

\section{Realistic origin of sports reform}

Finding out the principal contradictions existing in Chinese sports undertakings, sports reform theory and political logic of sports reform are the realistic origin of deepening sports reform, which also lay foundation for clarifying sports policies. It has been proved that all the important strategic deployment is closely related to the principal contradiction of real-time sports. For example, in the 1980s the judgment--"the lagged sports technology and the strategic objectives and demands to go global" are the principal contradictions to restrict sports development, laid initial foundation for the strategy of moderate advance development of competitive sports and the formation of "nationwide system" [4]. In the 1990s, Opinions on Deepening Sports Reform was published according to the location of "the contradiction between changing economic foundation and the current sports system". Starting form economic development and public demands, China is implementing transformation from planned economy and market economy. In 2015, per capita GDP in China reached 7,600 dollars, which means China is advancing gradually towards a well-off society. At present, varieties of sports associations have covered vast urban and rural areas and fitness centers and facilities can be seen everywhere. By the end of 2014 peasants sports fitness projects had been completed completely in 8 provinces, which had formed coverage in 79 percent of the administration villages in China. Calculated according to the statistics of the 6th national sports field investigation, every 20,000 people possess 30 stadiums, namely the average area of stadium is $1.45 \mathrm{~m} 2$. Even so, the problem of rare sports population can't be found yet. Finally it was raised that the principal contradictions of sports are continuously deepening, while national policies are only making surface adjustment. Without the reform of management mechanism and optimization of, the present situation of sports reform is difficulty to be changed.

\section{IMPETUS OF CHINESE SPORTS BASED ON THE BACKGROUND OF COMPREHENSIVELY DEEPENING REFORMS}

\section{A. Top-down reform impetus}

Top-down reform within the system was firstly raised by the People's Government, which displayed that the application of unshakable reform impetus was just perfect in sports reform. In sports reform, since the Party raised deepening the overall reforms of "five-in-one", behind the promotion of sports reform benefit appeals and responses of the masses were contained and the will performance of the government was surveyed. Sports reform should be of integrity and systematization, which will make the reform objective more explicit and distinct. "Promoting national governance system and governing capacity toward modernization" raised in the Third Plenary Session of the Eighteenth Party Congress made us realize the binding commitment of sports reform would be reduced and the governance goal would be more rational and advanced. Making a general observation of problems of sports 
reform, only with orientation, theory and route can we exert reform impetus on sports from top to bottom. The Party raised many requirements in the Third Plenary Session of the Eighteenth Party Congress, such as, accelerating the transformation of government function, optimizing government organization structure and establishing government of laws and service-oriented government [5]. Because of the implementation of various "lists of power" and "negative lists", the government power is restricted greatly. If the government's sense of responsibility can be intensified, efficiency of public service can be improved. Sports reform should seek for the maximization of public benefits, which can play the role of reform in sports practice only with the strong support of the government and public. Domestic scholars have probed deeply into sports concept, value orientation, structural form, operating mechanism, as well as institutional arrangements and main problems related to public sports service, and finally obtained definite theoretical replies, which shows the restriction of social knowledge on deepening the overall reforms disappeared.

\section{B. Bottom-up reform impetus}

Firstly, sports lack adequate socialization and marketization and sports resources offered to the public sports by the government can't satisfy the demand. When people maintain and realize their benefits, they will realize individual action is too weak, who formed "grass root" organizations to make interest articulations, thus deepening the urgency of sports reform. Secondly, sports socialization is the use of realizing function return, developing social sports talents and rectifying the sports resource shortage of the government. According to related statistics, there are 24,637 social organizations of sports registered officially in China. Sports social organizations are of great publicity and independence, which is especially of the important function in maintaining and realizing benefits and resolving conflicts. In service, sports social organizations can settle the problems of sports resource shortage for the government, thus improving the quality and efficiency of public service. In addition, the public are looking forward to sports reform, expressing in succession that there are such problems as incomplete public service system, undersupply of public sports resources, poor service quality and high charge of bodybuilding. Therefore, the public hold expectations for sports reform and participate in the reform actively, thus multiplying reform impetus.

\section{ROUTES OF CHINESE SPORTS BASED ON THE BACKGROUND OF COMPREHENSIVELY DEEPENING REFORMS}

\section{A. Government with sense of responsibilities.}

Deepening the overall sports reform depends on a promising government daring to undertake responsibilities completely. Firstly, the government should transform its function completely, which means "insisting on abandon what it should not take charge of", "taking less charge of what it needn't be responsible for" and "taking charge of what it can manage with resolution". In addition, the government should locate its role rationally in sports governance, weaken its sports function of "doing" and strengthen its sports function of "managing", then adjusting the sports benefits [6]. Secondly, to intensify the awareness of government public service, guarantee the predominance of government sports policies, transform government function actively and decentralize power and surrender profits are all realistic problems the government encounter and the index to survey a promising government with sense of responsibility. In addition, reforms in sports system, train system, competitive system and competitive sports promoted by the government are not so perfect, which are only the transition from the old system to the new one at most. To plan a new system, the government should reduce administrative intervention and can't monopolize the interests of professional sports. Then it should establish an institution of sports reform council to improve reform quality.

\section{B. Establish an effective market to realize function return}

The Party raised the important theory in the Third Plenary Session of the Eighteenth Party Congress, "promoting the market to play a decisive role in resource allocation", which fully proved people formed great common view on the practical level, and pointed out clearly that the key of reform lay in handling the relationship between the government and market in resource allocation appropriately [7]. Belonging to a special industry, sports industry must enter the market. According to the statics of Directive Opinions on Accelerating the Development of Sports Industry issued by the State Council in February, 2014: the total value added of sports industry was 121.4 billion yuan in 2010 , accounting for 0.51 percent of the total GDP; the total value added of sports industry was 258.3 billion yuan in 2011, accounting for 0.57 percent of the total GDP; the total value added of sports industry was 365.7 billion yuan in 2010, accounting for 0.64 percent of the total GDP. It is proved that the reform can achieve great success only by dealing with the relationship between the government and market appropriately.

\section{Cultivate organic society to improve efficiency}

Cultivating sports social organizations can not only enhance the efficiency of sports governance but accelerate the progress of deepening the overall reforms. Because of the relatively outstanding features of sports autonomy, sports autonomy system becomes the most attractive topic for the public. According to the analysis of Adjustment and Reform Scheme of Chinese Football Association issued in August, 2015, to make deep-level reforms, the sports social organizations should: clarify the interest relation and administrative relation between the government and sports social organizations; establish the governance structure related to target and location, self-management, definite function, selfeducation and self-service; supports economically the sports social organizations with outstanding qualification and capacity and formulate criterion for evaluation, which should be appraised by civil administrative departments, to stimulate and constrain sports social organizations and benefit the benign circle of sports governance. What's more, national sports institutions should provide sports social organizations with support in property right, authorized strength, funds and personnel and fully exert the social existence value of sports to contribute to Chinese sports. 


\section{CONCLUSION}

Based on the strategic deployment raised in deepening the overall reforms of the Third Plenary Session of the Eighteenth Central Committee, the real orientation and effective market of sports reform in our country should be clarified. Starting from the structural reform and mechanism transformation, we should optimize government, society and market operation mechanism, coordinate sports industries, like school sports, popular sports, competitive sports and professional sports, guarantee the development road of sports unblocked. Promoting sports management of the government, cultivating sports social organizations and implementing deepening the overall sports reforms are of paramount importance, whose transformation process and development mode need renovation and reform in all the progress and measure, which coincides with the objective, logic, impetus and route of Chinese sports reform with the background of exploring deepening the overall reforms.

\section{REFERENCES}

[1] He Qiang; Reform in Project Association in the Transformation of Sports Development Mode [J] Journal of Beijing University of Physical Education 2015, 1 (38):15-24.

[2] Bao Mingxiao; Strategy Research on Transforming the Development Mode of Chinese Competitive Sports [J] Journal of Beijing University of Physical Education2014, 1 (37):9-22.

[3] Bao Mingxiao; Chinese Route of Reform and Development of Professional Sports [J] Chinese Route of Reform and Development of Professional Sports, 2013, 3 (31):24-33.

[4] Zhang Jinqiao; Subject Heterogeneity Research on Commodity Supply of Public Service Product of Chinese Competitive Sports [J] Journal of Shenyang Institute of Physical Education,2015,1(34):1-9.

[5] Yu Shanxu; On Legal Dependence of Deepening Sports Reform on Modern Governance of Sports [J] Journal of Physical Education, 2015, 1 (22):1-8.

[6] He Qiang; On the Research of Several Fundamental Problems of Deepening the Overall Sports Reforms [J] Journal of Tianjin Institute of Physical Education, 2014, 2 (29):113-119.

[7] Liu Liang; The Logic, Objective, Impetus and Route of Sport Reform in China Based on the Background of Deepening the Overall Reforms [J] Sports Science, 2015, 10(35):10-16. 